\title{
Screening for Helicobacter pylori Infection among Asymptomatic University Students in Alexandria, Egypt, Using Non Invasive Laboratory Techniques
}

\author{
Hadir EL-Kady*
}

Department of Microbiology and immunology, Department of Medical Laboratory

Technology, Faculty of Allied Medical Sciences, Pharos University, Alexandria, Egypt

*Corresponding author

\begin{abstract}
A B S T R A C T
Globally, Helicobacter pylori (H. pylori) is becoming an increasingly troublesome economic and public health problem. Over $50 \%$ of the world's population was estimated to

\section{Keywords}

Helicobacter pylori, $H$. pylori stool antigen, $H$. pylori antibodies, chromatographic immunoassay, ELISA

Article Info

Accepted:

18 May 2018

Available Online:

10 June 2018 harbor H. pylori in the upper gastrointestinal tract (GIT) and over $80 \%$ of them reside in developing nations. Unless treated, colonization persists lifelong where $H$. pylori presents a key factor in the etiology of GIT diseases; ranging from asymptomatic chronic gastritis up to gastric carcinoma. Therefore, accurate and timely diagnosis is the first step to address this burdensome problem. The aim of this descriptive-cross sectional study was to compare two non-invasive techniques for the diagnosis of $H$. pylori infection among university students. Stool and serum samples were collected from one hundred asymptomatic students to detect $H$. pylori antigens (Ags) in stool using chromatographic immunoassay and $\mathrm{IgG}$ antibodies (Abs) in serum by enzyme linked immune sorbent assay (ELISA). Fifty five (55\%) of tested students were positive for each of stool Ags and serum Abs. The recorded sensitivity, specificity, positive predictive value (PPV) and negative predictive value (NPV) of the serum Ab test in relation to stool Ag test were 98.18\%, $97.78 \%, 98.18 \%$ and 97.78 , respectively. There was very good agreement (98\%) between the results of the two tests.
\end{abstract}

\section{Introduction}

Helicobacter pylori $(H$. pylori) discovered, as a human pathogen, by Marshall and Warren in 1982 (Marshall and Warren, 1984) is a gramnegative bacterium that colonizes the human stomach and can lead to chronic gastritis, peptic ulcer, gastric adenocarcinoma and mucosa-associated lymphoid tissue lymphoma besides causing other extra-digestive infections (McColl, 2010). A systematic review from 73 countries in 6 continents in
2018 revealed an overall prevalence of $44.3 \%$ worldwide. This rate ranged from 50.8 in developing countries to $34.7 \%$ in developed countries (Zamani et al., 2018). The prevalence rate differs considerably from one country to another and even within the same country, but overall, it is less frequent in developed countries than in developing ones in which prevalence rates of $>80 \%$ were reported previously (Yan et al., 2013, Hussain and Hamid, 2014, Whalen and Massidda, 2015, Perez-Perez et al., 2004). Childhood was identified as the critical time for 
acquisition of $H$. pylori infection and mothers probably play a key role in transmission (Taneike et al., 2001).

The exact mode of contracting $H$. pylori infection is not absolutely known, but personto-person (fecal-oral or oral-oral routes) is regarded as the main route of transmission of infection, followed by contaminated water and food (Sethi et al., 2013, Vale and Vitor, 2010). Iatrogenic transmission is another important mode of transmission, where tubes or endoscopes that have been in contact with gastric mucosa of an infected person are used for another one. Occupationally acquired infections were reported especially among endoscopists and gastroenterologists (Rastogi, et al., 2014).

The risk of acquiring $H$. pylori infection is related to socioeconomic status and living conditions early in life (Ravelomanana et al., 2013). In developing nations the majority of children are infected before the age of 10 (Malaty et al., 2002, Kivi et al., 2005) and adults probably harbor the same strain for several decades (Nourai et al., 2009). Around the world, infection rates reported among children ranged from approximately $35 \%$ in Russia, 20\% in China and Poland, $12 \%$ in Korea and America to $<10 \%$ in France, Belgium and Finland (Li et al., 2004).

In Egypt, prevalence of $H$. pylori infection is alarmingly high (Mohammad et al., 2008). Prevalence rates of $33 \%$ and $72.38 \%$ were reported among children less than 6 years and among school children, respectively (Frenck et al., 2006).

The prevalence of $H$. pylori infection is inversely related to standards of living, hygiene and sanitation (Hanafi and Mohamed 2013, Wangda et al., 2017). H. pylori is known for its intrafamilial clustering and is associated with crowded conditions (Krueger et al., 2015). Factors such as density of housing, overcrowding, number of siblings, sharing beds and lack of running water have all been linked to a higher acquisition of $H$. pylori infection. Within a particular country, the decline in prevalence of $H$. pylori tends to parallel the economic improvement and the active elimination of carrier ship by efficient antimicrobial therapy (Omosor et al., 2017).

Over $80 \%$ of the infected cases remain asymptomatic for decades (Alo et al., 2013), and only $30 \%$ of those infected are clinically symptomatic (Kusters et al., 2006). Presence of $H$. pylori is associated with an increased risk of various gastric pathologies including gastritis, duodenal and gastric ulcers, nonulcer dyspepsia, gastric adenocarcinoma and lymphoma (Zhong et al., 2016). According to Kusters et al., (Kusters et al., 2006), subjects infected with $H$. pylori develop peptic ulcer $(10-20 \%$ as lifetime risk) and stomach cancer (1-2\%). H. pylori was defined as a Class I carcinogen by the World Health Organization and the International Agency for Research on Cancer (Hu et al., 2016). Extradigestive diseases associated with $H$. pylori include autoimmune diseases, bronchiectasis, cardiovascular diseases, colonic and pancreatic diseases, diabetes mellitus, hepatobiliary system diseases, neurological diseases, skin diseases, infertility and hematological diseases (Pastukh et al., 2018).

There is no single test (other than histology from gastric biopsy) that can be set as a Gold Standard and optimal diagnostic technique for H. pylori infection. The only way to improve reliability of diagnosis is to apply for a multidiagnostic tool (Islam et al., 2010, Sethi et al., 2013).

The diagnostic tests for $H$. pylori infection can be classified into two categories: invasive and non-invasive tests. Invasive (biopsy-based) tests require upper gastrointestinal (GIT) 
endoscopy and include: histological examination, culture, rapid urease test (RUT), polymerase chain reaction (PCR) and fluorescent in situ hybridization (FISH). Invasive tests require use of specialized equipment by experienced personnel and a long time to get results (El Khadir et al., 2016).

Non-invasive assays are cheaper, more comfortable and safer in comparison to invasive methods. Non-invasive techniques are categorized into two groups of direct and indirect tests. Stool antigen test (SAT) is a direct non-invasive test where the presence of $H$. pylori antigens is directly evaluated. Testing for the presence of antibodies (Abs) against $H$. pylori in serum, saliva and urine samples or other elements like $\mathrm{CO}_{2}$ that result from $H$. pylori infection is classified as an indirect non-invasive technique. Those tests include 13C- urea breath test (UBT) and serologic assays (Ranjbar et al., 2017). Inspite of the high sensitivity (88-95\%) and specificity of UBT (95-100\%) it has many limitations including its high cost, need of trained staff and equipped laboratory equipment, patients must fast before testing and proton pump inhibitor (PPI) administration before testing results in false negative results as it alters the gastric $\mathrm{pH}$ and thus lowers urease activity of $H$. pylori (Shimoyama, 2013).

Serological tests were designed for detecting specific Abs such as anti-H. pylori immunoglobulin (Ig) $\mathrm{G}$ or anti-CagA and antiVacA Abs (Ranjbar et al., 2017). According to the type of serological tests, their recorded sensitivity was up to $90 \%-97 \%$ and their specificity varied from $50 \%$ to $96 \%$ (Bytzer et al., 2011). Serological tests are in fact not able to distinguish active infection from previous contact; with a $30 \%$ false positive rate, as Ig G detection indicates both previous (treated) and current infections. To avoid detection of past
H. pylori infection, the UBT and SAT are preferred (Sethi et al., 2013).

H. pylori SAT is used on a wide scale as a simple, cheap and feasible noninvasive technique to diagnose and follow-up $H$. pylori infection (Lario et al., 2016, Osman et al., 2014). Two types of SATs; one based on enzyme immunoassay (EIA) and another on chromatography (ICA) ARE PRESENT (Shimoyama, 2013). A sensitivity and a specificity of up to $95 \%$ have been recorded in several reports (Malfertheiner et al., 2012, Ranjbar et al., 2017) and positive and negative predictive values of $100 \%$ and $96.5 \%$ have also been reported (Gulcan et al., 2005). There are two methods for antigen detection based on monoclonal and polyclonal antibodies. In polyclonal antibody method, cross reactivity of the H. pylori SA with non-viable or coccoid forms of the $\mathrm{H}$ pylori may result in falsepositive results (Elitsur et al., 2004).

The monoclonal antibody test was reported to have higher sensitivity than the polyclonal antibody (98\% vs. 93.8\%) (Sharbatdaran et al., 2013). This test is suitable to monitor the success of anti- H. pylori therapy and in screening of asymptomatic subjects (El-Nasr et al., 2003). The test was approved by the United States Food and Drug Administration (FDA) as a pre-endoscopic diagnostic test for $H$. pylori infection in adults. A new generation of rapid monoclonal antibody based $H$. pylori SAT that works with lateral flow immunochromatography technique in 5 minutes is now available (Yang et al., 2008). They were reported as the most effective screening tests both in populations of high and low prevalence of $H$. pylori infection (Queiroz et al., 2013, Cardenas et al., 2008).

The accuracy of SATs is diminished when stool samples are watery or unformed due to dilution of $H$. pylori antigens. Temperature and time gap between sample collection and 
testing also influences results (Shimoyama, 2013).

Regarding the broad spectrum of available $H$. pylori diagnostic tests and since a reliable diagnosis is mandatory both before and after eradication therapy; it is crucial to evaluate the broad spectrum available $H$. pylori diagnostic methods to be able to select the most accurate diagnostic laboratory tests that could be used for efficient diagnosis of $H$. pylori infection (Leal et al., 2008, Tameshkel et al., 2018, Shimoyama, 2013). Diagnostic and predictive values besides the cost-effectiveness of tests help to choose the optimal methods

From the public health aspect, determination of prevalence rates, identification of high-risk population and confirmation of risk factors for $H$. pylori infection are crucial to establish health policies and treatment strategies to prevent $H$. pylori related diseases. This is even more important for people who are harbouring H. pylori but are asymptomatic (Rastogi et al., 2014).

The current study was carried out to evaluate two non-invasive techniques $(H$. pylori SAT using rapid chromatographic immunoassay and $H$. pylori IgG in serum by ELISA technique) in detection of $H$. pylori prevalence rate among a sector of asymptomatic university students. The study also aimed to find out the relationship between $H$. pylori infection and some personal and environmental risk factors.

\section{Materials and Methods}

\section{Study design, sample size and study setting}

A cross-sectional descriptive study was conducted at the Medical Laboratory Technology Department of the Faculty of Allied Medical Sciences, Pharos University (PUA), Alexandria, Egypt in the period from
September to December 2017. One hundred university students were recruited in this casecontrol study. They comprised 60 males and 40 females; within the age range of 17 to 24 years. The enrolled students admitted they didn't suffer any GIT symptoms suggestive of $H$. pylori infection (anorexia, nausea, vomiting, diarrhea, heart burn, epigastric pain, indigestion, bloating, bleeding, weight loss), persistent for one month at least within the past three years. The exclusion criteria included previous diagnosis for $H$. pylori infection, gastritis, gastric or duodenal ulcers and/or treatment with $\mathrm{H} 2$ blockers, PPI, antibiotics (commonly used in treatment of $H$. pylori, including metronidazole), steroids or non-steroidal anti-inflammatory drugs (NSAIDS) during the past three months. Written consents were signed by volunteer students and they filled in questionnaires that included questions covering demographic data (age, sex, and residence), socioeconomic data (monthly income, crowding index), lifestyle, dietary habits, past history of $H$. pylori infection and eradication therapy. This study received ethical approval from the High Institute of Public Health (HIPH) Ethics Committee.

\section{Samples collection and processing}

Fresh stool samples provided in sterile containers were immediately sent to the microbiology laboratory of the Medical Laboratory Technology department at Faculty of Allied Medical Sciences. Exclusion criteria of the provided samples were non formed stool, inadequate amount and delayed delivery after collection. Examination of the stool samples to detect $H$. pylori antigen was performed using rapid chromatographic Immunoassay (ABON one step test code no: 1155976703) (ABON Biopharm Co 2012). Small portions; collected from three different sites of every stool sample (adding up to 50 $\mathrm{mg}$, approximately) were transferred to the 
sample collection tube containing extraction buffer. After two minutes of vigorous shaking and after two other minutes of resting the tube, two full drops were dropped into the round window of the test cassette. Reading followed 10 minutes of incubation at room temperature.

\section{Interpretation of the results}

The appearance of two colored lines across the central window of the cassette, $\mathrm{C}$ (control) and $\mathrm{T}$ (test) zones or appearance of a pale colored line in $\mathrm{T}$ zone indicated a positive test. Only one line in $\mathrm{C}$ zone indicated a negative result. Test result was considered invalid in cases where no line appeared in $\mathrm{C}$ line zone.

The collected sera were stored frozen at $-20^{\circ} \mathrm{C}$ until used for detection of serum H. pylori $\mathrm{IgG}$ using the commercially available Immunospec Helicobacter pylori IgG ELISA kit (Catalog No.E30-145) (Immunospec Co 2006). ELISA was performed following the manufacturer's instructions.

\section{Qualitative results}

The cut-off control corresponds to calibrator one. If the absorbance of the sample was higher than that of the cut-off, the sample was considered positive for the presence of specific IgG. The ratio between optical density (OD) value of the sample and that of the cutoff was calculated. Repeated freezing and thawing of sera was avoided.

\section{Statistical Analysis}

Data were analyzed using IBM SPSS software package version 20.0 (Kirkpatrick and Feeney, 2013). Qualitative data were described using number and percent. Comparison between various groups regards categorical variables was tested using Chi-square test. When more than $20 \%$ of the cells had expected count below 5, correction for chi-square was conducted using Fisher's exact test or Monte Carlo tests. Significance of the obtained results was judged at the 5\% level. Calculation of sensitivity and specificity of tests were also chosen at the optimal cut off which has a highest positive likelihood ratio (+LR)

\section{Where ${ }^{*} \mathrm{LR}=\frac{\frac{\text { Sensitivity }}{1-\text { Specifity }}}{\mathrm{FP} \text { rate }}$}

The agreement between the tests was analyzed using Kappa coefficiency test.

\section{Results and Discussion}

The discovery of $H$. pylori by Warren and Marshall in 1982 was preceded by nearly a hundred years of inconspicuous publications in regard to spiral bacteria, achlorhydria, gastritis, gastric urease, and antimicrobial therapy for peptic ulcers. The infection has now been involved in the etiopathogenesis of chronic gastritis, peptic ulcer, gastric cancer and gastric MALT lymphoma. (Jemilohun and Otegbayo, 2016)

Epidemiologic studies have shown that $50 \%$ of adults in the developed countries and nearly $90 \%$ of adults in the developing countries carry $H$. pylori in their upper GIT; making it the most widespread infection in the world (Silva Rossi, et al., 2009) Although over 80\% of cases present with asymptomatic infection, $H$. pylori infection can cause gastric and peptic ulcer disease and is a cofactor in gastric cancer; therefore, an accurate and reliable method for diagnosis is mandatory (Ahmed and Shammari, 2015).

Previous studies on the prevalence of $H$. pylori published worldwide reported variable infection rates. The main reason for this variation was the socioeconomic difference between such populations. Lack of proper sanitation, safe drinking water and basic hygiene, besides; poor diet and overcrowding, 
all play a role in determining the overall prevalence of infection (Azevedo et al., 2009, Ibtihal, 2010). It also seems that prevalence rates depend not only on the rate of acquisition but also on the rate of loss of infection and the duration between acquisition and loss (Muhammad et al., 2012).

In the current study, a total of 100 university students were recruited, out of whom $60 \%$ were males and $40 \%$ were females. The age of the participants ranged from 17 to 26 years old. The overall prevalence of $H$. pylori infection recorded was $55 \%$.

Results of the present study revealed a prevalence rate of $55 \%$ for $H$. pylori infection among asymptomatic university students. Different results were reported among Egyptians as those reported by Hassanein et al., (Hassanein et al., 2017): 24\% and by Sabah et al., (Sabah et al., 2015): 69.4\%. The present prevalence rate was in line with results reported in previous studies carried out in African countries as that in Nigeria $: 52.5 \%$ (Omosor et al., 2017) and these carried out in Libyia : 54.4\% (Almehdawi, 2016) and 56.5\% (Almehdawi and Ali, 2016). Higher percentages were reported in Ethiopia: $70 \%$ (Alebie and Kaba, 2016), Libyia: 76\% (Bakka and Saleh, 2002), Nigeria: 80\% (Oluwasola, 2002), Tunis: 83\% (Ben Ammar et al., 2003), Morocco: 92.65\% (Bounder et al., 2017) and in a public survey carried out also in Nigeria 93.6\% (Olokoba et al., 2013).

The recorded percentages in studies carried out in Asian countries, for screening for $H$. pylori infection among asymptomatic subjects, varied from as low as $13.1 \%$ in Iran (Namakin and Nejad, 2014), Lebanon (21\%) (Naous et al., 2007), India (46\%) (Rastogi et al., 2014), Saudi Arabia (51\%) (Mubashir and Ghazi, 2007), Korea (54.4\%) (Lim et al., 2013), China (63.4\%) (Zhu et al., 2014), Oman (69.5\%) (Al-Balushi et al., 2013) to as high as
$82.5 \%$ in Turkey (Ozaydin et al., 2013).

Even in developed countries variable rates of $H$. pylori infection were reported among asymptomatic subjects as in Portugal: $84.2 \%$ (Bastos et al., 2013), Mexico: 52.2\% (Alvarado-Esquivel, 2015), Brazil: 41.1\% (Pacheco, et al., 2013), Canada: 37.9\% (Sethi et al., 2013), Netherlands: 32\% (van Blankenstein, et al., 2013), USA: $25.4 \%$ (Krueger et al., 2015) and Belgium: 11\% (Mana et al., 2013). In Japan, the prevalence recorded was near 90\% among individuals born before 1950s, with a subsequent decreasing trend, reaching less than $2 \%$ among subjects born after 2000s (Inoue, 2017). The decline in prevalence is an indication of improvement of socio-economic status, hygiene and sanitation and the active eradication of carrier ship by proper antibiotic treatment (Kingsley et al., 2017).

It is actually difficult to compare the prevalence rates indifferent studies due to variations in age and the sector of population studied. Comparing the results of the present study to those of previous studies performed to screen for $H$. pylori infection specifically among asymptomatic university students; nearly similar percentages were reported among Nigerian university students: $54 \%$ (Ishaleku and Ihiabe, 2010) and among Irish ones: 59\% (Sheehan et al., 2004). Lower prevalence rates were reported among the same sector in Brazil: 23.4\% (Melo et al., 2003) and Saudi Arabia: 35\% (Almadhi et al., 2007). A higher prevalence rate of $71 \%$ was reported among Ethiopian university students (Alebie and Kaba, 2016). Nevertheless, the prevalence rate variations observed between the current report and others may be attributed to differences in methodology and technical factors as well as level of sanitation and social economic status of individual subjects screened.

The high prevalence of this bacterial infection 
among university students indicates that the major public health problem of peptic ulcer disease and gastric cancer in the society will be difficult to be eradicated since this age group is engaged in high interpersonal social activities; which enhances the transmission of $H$. pylori infection.

In the current study although the prevalence rate was higher among females (70\%) than among males (45\%); yet no significant difference between both sexes was reported $\left(\chi^{2}=6.061 ; p=0.014\right)$. [Table 1]

The relationship between gender and $H$. pylori infection has been controversial in other studies (Yordanov et al., 2017, Yu et al., 2017). A systematic review with meta-analysis carried out in 2018 reported that no significant difference was observed between the two genders in worldwide $H$. pylori prevalence (Zamani et al., 2018). The role of sex to put males at significantly higher risk of $H$. pylori infection compared to females was observed in many previous studies (Ibrahim et al., 2017, Valliani et al., 2015, Omosor et al., 2017, Jeong et al., 2007, Kaore et al., 2012). Nevertheless, such trend contradicted the present and other studies' findings; where gender was not significantly associated with H. pylori infection (Seyda et al., 2007, Mathewos et al., 2017, Tadege et al., 2005). Non-significant higher prevalence rates among females were similarly previously reported in many studies (Munish et al., 2014, MontazerSaheb et al., 2011, Almehdawi and Ali 2016, Alemayehu 2011, van Blankenstein et al., 2013, Adlekha et al., 2013, Vilaichone et al., 2013, Dorji et al., 2013, Benajah et al., 2013, Mathewos et al., 2013, Omosor et al., 2017)

Thirty five out of the 100 students screened in the current work (35\%) came from urban areas while $65(65 \%)$ came from rural areas. Prevalence rate of $H$. pylori infection among urban dwellers was $54.3 \%$ (19/35) compared to $55.4 \%(36 / 65)$ in rural dwellers. Residence was not significantly associated with prevalence of $H$. pylori. This finding is in line with previous studies carried out in Egypt, Mexico and Lybia (Mohamed et al., 2016, Laszewicz et al., 2014, Almehdawi et al., 2016). On the other hand, several researchers reported a positive correlation between rural life and $H$. pylori infection (Abdallah et al., 2014, Lim et al., 2013, Vilaichone et al., 2013, Hanafi and Mohamed 2013). This could be attributed to inadequate sanitary conditions and to absence or poor personal hygiene

Eighty seven $(87 \%)$ of the current participants were classified as middle socioeconomic class and only 13 (13\%) belonged to the high socioeconomic class; according to modified score for social leveling of families (Fahmy et al., 2015). There was a high significant association between the socioeconomic standard of the students and their parents and the prevalence of $H$. pylori among them. The prevalence rate was higher in medium than in high socioeconomic groups (84.65 and 39.1\%, respectively).

This finding is consistent with previous studies carried out in Egypt and other countries which have demonstrated that the prevalence of $H$. pylori was higher in those who come from large families, had poor hygiene, limited living standards, poor sanitary practices and overcrowded living conditions (Hassanein et al., 2017, Rastogi et al., 2014, Mohammad et al., 2011, Dattoli et al., 2010). Salih et al., (2009), noted that overcrowded conditions entailing closer contact between individuals sharing the same bed is important factor for the acquisition of such infection. In contrast, Mclaughlin et al., (2003) found no association between the prevalence of $H$. pylori and socioeconomic standard in Zambia. Socioeconomic status is not restricted to income and social class but also other factors such as living standards, 
urbanization and educational level are major determinants of $H$. pylori prevalence (Khalifa et al., 2010, Naous et al., 2007, Eshraghian, 2014).

Regarding family history of $H$. pylori infection and related gastritis, it was mentioned by $30(30 \%)$ of the students screened in the present study and denied by 70 (70\%) of whom. H. pylori prevalence among those with family history of $H$. pylori (especially infection of the mother) was $70 \%$ (21/30) compared to $48.6 \%$ (34/70) among others.

The difference between both groups was statistically significant $\left(\chi^{2}=3.896 ; p=0.048\right)$. It is worth mentioning that in the 21 cases with positive family history; it was the mother who had $H$. pylori infection.

Fathers tend to have less contact with their siblings than mothers, so they are less involved in the transmission (Fujimoto et al., 2007). It was reported that the relative risk of a person becoming infected with $H$. pylori is approximately four or eight times greater; when the father or the mother is infected, respectively (Manfredi et al., 2016). Molecular studies carried out to trace intrafamilial transmission confirmed the mother-to-child transmission in most cases and further reported a grandmother-to-child transmission. (Didelot et al., 2013, Osaki et al., 2013, Urita et al., 2013). It seems that mothers could transmit the infection through mouth secretions; using common spoons or tasting the food.

Furthermore, interfamilial transmission may be also responsible for re-infection with $H$. pylori as its presence among asymptomatic family members may facilitate the transmission among households (Manfredi et al., 2013, Ryu et al., 2010). Several previous studies consistently supported infected siblings as a risk factor for $H$. pylori infection among families (Dattoli et al., 2010, Fialho et al., 2010, Muhsen et al., 2010, Cervantes et al., 2010, Nam et al., 2011).

Regarding unhealthy eating habits, 53 (53\%) of the students shared articles like: spoons, glasses and plates with their family members and/or roommates compared to 47 (47\%) who didn't share articles. Sharing articles with family members or room-mates was not significantly associated with a higher prevalence rate of $H$. pylori infection among the screened students in the present work. This finding is consistent with those reported in Egypt, Libyia and Turkey (Mohamed et al., 2016, Almehdawi and Ali 2016, Kaya et al., 2014).

An inverse association between the level of the parents' (mother's) education and $H$. pylori infection among the studied students was reported in the current work. H. pylori prevalence recorded among students whose mothers had only primary school education was $89.5 \%(17 / 19)$ compared to $65.1 \%$ (28/43) among those whose mothers had high school education and to only $26.3 \%$ (10/38) among those whose mothers achieved university education or higher. This variance was highly statistically significant $\left(\chi^{2}=25.534\right.$; $\mathrm{p}<0.001)$.

The same association was reported in other similar studies (Bastos et al., 2013, Mana et al., 2013).

Among the lifestyle habits common among university students; smoking showed a high significant association with $H$. pylori infection among the students screened in this work. The prevalence of $H$. pylori recorded among smokers was $80.4 \%$ (37/46) compared to $33.3 \% \quad(18 / 54)$ among non-smokers. $\left(\chi^{2}=22.266 ; \mathrm{p}<0.001\right)$. 
Table.1 Relation between $H$. Pylori prevalence and different parameters

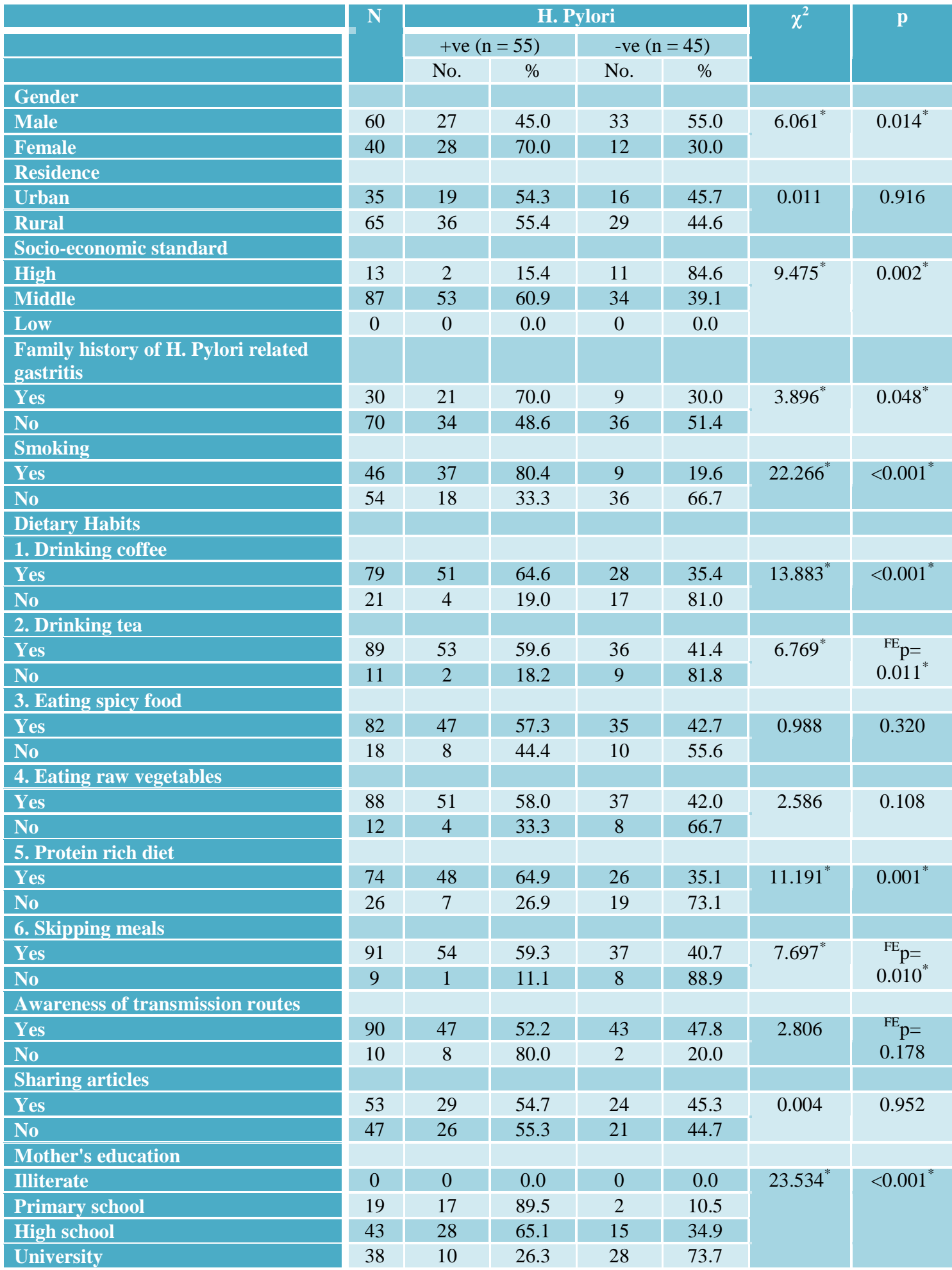

$\chi^{2}$ : Chi square test for comparing between the two categories

${ }_{\mathrm{FE}}^{\mathrm{p}} \mathrm{p}$ v value for Fisher Exact for Chi square test for comparing between the two categories

$*$ : Statistically significant at $\mathrm{p} \leq 0.05$ 
Table.2 Relationship between results of H. Pylori stool Ag test and serum test among the 100 studied students

\begin{tabular}{|c|c|c|c|c|c|c|}
\hline \multirow{2}{*}{$\begin{array}{l}\text { Stool Ag results } \\
\text { Serum test results }\end{array}$} & \multicolumn{2}{|c|}{ Stool Ag } & \multirow[t]{2}{*}{ Sensitivity } & \multirow[t]{2}{*}{ Specificity } & \multirow[t]{2}{*}{ PPV } & \multirow[t]{2}{*}{ NPV } \\
\hline & -ve & +ve & & & & \\
\hline Serum test -ve & 44 & 1 & \multirow[t]{2}{*}{98.18} & \multirow[t]{2}{*}{97.78} & \multirow[t]{2}{*}{98.18} & \multirow[t]{2}{*}{97.78} \\
\hline Serum test +ve & 1 & 54 & & & & \\
\hline Total & 45 & 55 & & & & \\
\hline$\kappa(p)$ & \multicolumn{2}{|c|}{$0.960 *\left(<0.001^{*}\right)$} & & & & \\
\hline Level of agreement & \multicolumn{2}{|c|}{ Very good } & & & & \\
\hline$\%$ of agreement & \multicolumn{2}{|c|}{$(44+54) / 100 \%=98 \%$} & & & & \\
\hline
\end{tabular}

\begin{tabular}{|c|c|}
\hline \multicolumn{1}{|c|}{ Value of $\mathbf{K}$} & Strength of agreement \\
\hline$<0.20$ & Poor \\
\hline $0.21-0.40$ & Fair \\
\hline $0.41-0.60$ & Moderate \\
\hline $0.61-0.80$ & Good \\
\hline $0.81-1.00$ & Very good \\
\hline
\end{tabular}

Other authors also reported that smokers were at higher risk of acquiring $H$. pylori infection. (Hanafi and Mohamed, 2013, Ozaydin et al., 2013, Alebie and Kaba 2016). On the other hand, in most studies, there was no significant association between smoking and $H$. pylori infection (den Hollander et al., 2013, Zhu et al., 2014, Sodhi et al., 2013, Almehdawi, 2016, Almehdawi and Ali, 2016, Camargo et al., 2004).

The absence of association in such studies may be due to less number of smokers screened, besides the type of tobacco and the frequency of smoking. Smoking was implicated to promote virulent infection in individuals by inducing the expression of virulent genes, including cag $\mathrm{A}, \mathrm{E}$ and $\mathrm{T}$ (Ghosh and Bodhankar, 2012).

As regards the dietary habits of the participants in the current work; drinking coffee and tea, intake of high protein diet and skipping meals were significantly implicated to increase the risk of $H$. pylori infection. $(p<0.05)$ This finding coincided exactly with the results of screening university students in Ethiopia (Alebie and Kaba, 2016).

Skipping meals was previously reported to have a significant association with $H$. pylori infection rates. As for protein rich food stuffs, it was postulated that $H$. pylori could survive in some animal products rich in protein, including meat and dairy products at temperature below $30^{\circ} \mathrm{C}$. Moreover, such foods could serve as source of amino acids which support the growth of this bacterium in the stomach (Abu Farsakh, 2002).

Drinking coffee supports the growth of $H$. pylori by suppressing acid production in the stomach. Coffee drinking was also claimed to be involved in hyper stimulation and increased levels of stress related hormones such as cortisol, adrenaline and norepinephrine (Almehdawi, 2016); which in turn could negatively influence the activity of the immune system supposed to combat $H$. pylori. On the other hand, Rana (2007) 
reported tea consumption as a protective factor against $H$. pylori infection.

On the other hand, neither eating spicy food nor raw vegetables was significantly associated with a higher $H$. pylori prevalence in the present work. This is in line with the findings of a Libyan study (Almehdawi, 2016) and disagrees with those of another Libyan study; which reported a higher prevalence rate of $H$. pylori among the groups eating raw vegetables (Bakka et al., 2009).

Although infection rate among those students who were not aware of the transmission routes of $H$. pylori was far beyond that among those who were aware of such routes $(80 \%$ (8/10) and 52.2\% (47/90), respectively); yet the difference was not statistically significant.

This contradicted the findings of a similar study applied on Ethiopian university students.(Alebie and Kaba, 2016) Awareness creation in the community about good personal hygiene and environmental sanitation is the first step towards the control of $\mathrm{H}$. pylori contamination of food and water sources (Salih, 2009).

H. pylori infection remains the most frequent and persistent bacterial infection worldwide; thus the need for an accurate diagnosis of infection is imperative. The ideal test for detection of $H$. pylori infection should be noninvasive, highly accurate, widely available and inexpensive (Jafar et al., 2013).

The invasive techniques for diagnosis of $H$. pylori are difficult, expensive and not preferred by the patients (Ni et al., 2000). So, a rapid and cost-effective detection method for diagnosis of $H$. pylori infection is required. Therefore, non-invasive testing for $H$. pylori has been strongly recommended as it is cheaper, more patient friendly than invasive methods and does not require very complicated laboratory facilities (Osman et al., 2014).

Stool Ag test is one of the non-invasive methods that is broadly used in the diagnosis of $H$. pylori infection and had been known for the accuracy of its results and comparability to invasive methods (Ni et al., 2000). In the current research, H. pylori stool Ag test was considered the gold standard method for diagnosis of $H$. pylori infection. This is attributed to its previously reported high sensitivity and specificity (up to 97\%) (Bakri 2012, Pourakbari et al., 2013, GarzaGonzález et al., 2014, Jekarl et al., 2013,) and its excellent positive and negative predictive values regardless of $H$. pylori prevalence (Bakri 2012).

Compared to UBT, stool Ag test was reported by Frenck et al., (Frenck et al., 2006) at Cairo University to be equivalent to its sensitivity and specificity. They concluded that UBT and stool Ag test had comparable high sensitivity (98 and 94\%, respectively) and specificity (89\% and $81 \%$, respectively) and thus the stool $\mathrm{Ag}$ test has been evaluated as equivalent to the UBT.

In addition to stool Ag test, serological tests are also useful non-invasive methods for the diagnosis of $H$. pylori infection. They are acceptable by patients because of their noninvasiveness; quick results, less liability to be affected by colloidal bismuth, PPIs, or antibiotics (Shah et al., 2014).

In comparison to the biopsy-based tests; review of the overall performance of the commercially available serology kits that measure IgG antibodies highlighted that serology is an accurate method of diagnosing $H$. pylori infection. Comparison between serology and the combination of the rapid urease test: Campylobacter-like organism test (CLO), histology and culture showed up to 
$97.8 \%$ sensitivity and $100 \%$ specificity (Abasiyanik et al., 2002).

In the present study, immunochromatographic assay was used for detection of stool $\mathrm{Ag}$ as it has the advantage of rapid report of results within minutes and it does not need the use of expensive laboratory equipment. The test was positive in 55/100 of the screened students (55\%). All collected stool samples in the current work were well formed which could be the reason for the enhanced stool Ag test results, because the results of this test are inaccurate when stool samples are unformed or watery, as $H$. pylori specific Ags are diluted (Shimoyama, 2013).

In addition, students in the present study were also screened for $H$. pylori using the serum IgG Ab test (Immunospec Helicobacter pylori IgG ELISA).

Out of the 100 students screened for $H$. pylori in the current work, 55\% (55/100) were positive for both stool $\mathrm{Ag}$ test and serum $\mathrm{Ab}$ test; 54 of whom were simultaneously positive for both tests while only 1 was positive for stool Ag test but negative for serum $\mathrm{Ab}$ test and another one was positive for serum $\mathrm{Ab}$ test but negative for stool $\mathrm{Ag}$ test. This can be explained by the fact that a negative result does not confirm the absence of Abs to $H$. pylori. Early stages of colonization may be present or the Ab titer may be too low for the assay to detect. Similar findings were reported by Couturier (Couturier, 2013) and Mohamed et al., (Mohamed et al., 2016).

Compared to the stool Ag test, a sensitivity, specificity and agreement of 98.18, 97.78 and $98 \%$, respectively were recorded for serum IgG $\mathrm{Ab}$ test (Table 2)

These results were in accordance with the findings of Pandya et al., (Pandya et al.,
2014), who reported that the $\operatorname{IgG} A b$ test evaluated in their study, had a sensitivity of $100 \%$, which permits the safe use of this test in screening surveys. Unlikely, Shah et al., (Shah et al., 2014), reported that serum IgG sensitivity ranged from 90 to $97 \%$, but the specificity ranged from 50 to $96 \%$. In addition, Iqbal et al., (Iqbal et al., 2013), reported a higher specificity rate of $80 \%$.

Considering the substantial efforts that $H$. pylori is forcing us daily, both to avoid serious complications as peptic ulcer and gastric cancer and the consequent extensive financial burden, it is recommended to take accurate steps towards screening for this infection on a wide scale and to adopt a strategy to prevent and eradicate it, globally.

\section{Acknowledgment}

I would like to express my deep thanks and sincere appreciation to my dear professors, students and colleagues for their kind efforts performed in this study. I would also like to extend my hearty thanks and deepest gratitude to the laboratory specialists of the medical laboratory technology department at the Faculty of Allied Medical Sciences; Pharos University, Alexandria, Egypt.

\section{References}

Abasiyanik, M.F., Sander, E., Salih B.A. 2002. Helicobacter pylori anti-CagA antibodies: Prevalence in symptomatic and asymptomatic subjects in Turkey. Can. J. Gastroenterol., 16(8):527-32.

Abdallah, T., Mohammed, H., Hammed, A, et al., 2014. Sero-prevalence and factors associated with Helicobacter pylori infection in Eastern Sudan. Asian Pac. J. Trop. Dis. 4(2):115-9.

ABON Biopharm Co., 2012. ACON H. Infectious disease antigen detection. China: ABON BIOPHARM 
(HANGZHOU) CO., LTD. available from:

http://www.abon.com.cn/Product/Index/ 15080715055791.

Abu Farsakh, N.A. 2002. Risk factors for duodenal ulcer disease. Saudi. Med. J., 23(2):168-72

Adlekha, S., Chadha, T., Krishnan, P., et al., 2013. Prevalence of Helicobacter pylori infection among patients undergoing upper gastrointestinal endoscopy in a medical college hospital in kerala, India. Ann. Med. Health Sci. Res. 2013; 3:559-63.

Ahmed, S.A., Al Shammari, H.N. 2015. Helicobacter pylori infection: seroprevalence and detection of $H$. pylori $\mathrm{IgG}$ by using ELISA. Inter. $J$. Immunol., 3:21-6.

Al-Balushi, MS., Zal-Busaidi, J., Al-Daihani, M.S., et al., 2013. Sero prevalence of Helicobacter pylori infection among asymptomatic healthy Omani blood donors. Asian Pac. J. Trop. Dis. 3(2): 146-9.

Alebie, G., Kaba, D. 2016. Prevalence of Helicobacter Pylori Infection and Associated Factors among Gastritis Students in Jigjiga University, Jigjiga, Somali Regional State of Ethiopia. $J$. Bacteriol. Mycol., 3 (3):60.

Alemayehu A. 2011. Seroprevalence of Helicobacter pylori Infection and Its risk factors among adult patients with dyspepsia in Hawssa teaching and referral hospital, South Ethiopia. Addis Ababa University: Ethiopia.

Almadhi, M., Aljebreen, A.M., Tounesi, F., et al., 2007. Helicobacter pylori prevalence among medical students in a high endemic area. Saudi. Med. J., 28(6):896-8.

Almehdawi, K.H., Ali, A. 2016. The Prevalence of Helicobacter Pylori Infection in Benghazi, Libya. IOSRJDMS., 15(7):73-7.
Alo, M.N., Alhassan, H.M., Saidu, A.Y., et al., 2013. The Prevalence of Helicobacter Pylori Infection in Asymptomatic Persons in Ethiope East Local Government Area, Delta State, Nigeria. Int. J. Pub. Health Pharm., 1(1):115-119.

Alvarado-Esquivel, $\quad$ C. 2013. Seroepidemiology of Helicobacter pylori infection in pregnant women in rural durango. Mexico. Int. J. Biomed. Sci., 9:224-9.

Azevedo, N.F., Huntington, J., Goodman, K.J. 2009. The Epidemiology of Helicobacter pylori and Public Health Implications. Helicobacter, 14 (Suppl. 1): $1-7$

Bakka, A., Mohamed, A., Altayar, M., et al., 2009. Helicobacter pylori infections among Libyan chronic dyspeptic patients in Benghazi. L. J. Infect. Dis., 3 (2).

Bakka, A.S., Salih, B.A. 2002. Prevalence of Helicobacter pylori infection in asymptomatic subject in Libya. Dign, Microbiol, Inf. Dis, 43:265-8

Bakri, M.M. 2012. Evaluation of non-invasive diagnostic tests for Helicobacter pylori infection in symptomatic patients and healthy volunteers. Pak. J. Physiol., 8(2):10-12.

Bastos, J., Peleteiro, B., Barros R., et al., 2013. Sociodemographic determinants of prevalence and incidence of Helicobacter pylori infection in Portuguese adults. Helicobacter. 18(6):413-22.

Ben Ammar, A., Cheikh, I., Kchaou, M., et al., 2003. Prevalence of Helicobacter pylori infection in normal or asymptomatic patients. Tunis. Med., 81(3):200-04.

Benajah, D.A., Lahbabi, M., Alaoui, S., et al., 2013. Prevalence of Helicobacter pylori and its recurrence after successful eradication in a developing nation 
(Morocco). Clin. Res. Hepatol. Gastroenterol. 37:519-26.

Bounder, Gh., Boura, H., Nadifiyine, S., et al., 2017. Epidemiology of Helicobacter pylori Infection and related gastric pathologies in Moroccan population. $J$. Life Sci., 11:211-218.

Bytzer, P., Dahlerup, J.F., Eriksen, J.R., et al., 2011. Diagnosis and treatment of Helicobacter pylori infection. Dan. Med. Bull., 58:C4271.

Camargo, M.C., Lazcano Ponce, E., Torres, J., et al., 2004. Determinants of Helicobacter pylori seroprevalence in Mexican adolescents. Helicobacter. 9(2):106-14.

Cardenas, V.M., Dominguez, D.C., Puentes, F.A., et al., 2008. Evaluation of a novel stool native catalase antigen test for Helicobacter pylori infection in asymptomatic North American children.

J. Pediatr. Gastroenterol. Nutr., 46:399-402.

Cervantes, D.T., Fischbach, L.A., Goodman, K.J., et al., 2010. Exposure to Helicobacter pylori-positive siblings and persistence of Helicobacter pylori infection in early childhood. $J$ Pediatr Gastroenterol Nutr., 50:481-5.

Couturier, M.R. 2013. The evolving challenges of Helicobacter pylori disease, diagnostics, and treatment, part 1. Clin. Microbiol. Newsletter., 35(3):19-23.

Dattoli, V.C., Veiga, R.V., da Cunha, S.S., et al., 2010. Seroprevalence and potential risk factors for Helicobacter pylori infection in Brazilian children. Helicobacter. 15:273-8.

Den Hollander, W.J., Holster, I.L., den Hoed, C.M., et al., 2013. Ethnicity is a strong predictor for Helicobacter pylori infection in young women in a multiethnic European city. J. Gastroenterol. Hepatol., 28:1705-11
Didelot, X., Nell, S., Yang, I., et al., 2013. Genomic evolution and transmission of Helicobacter pylori in two South African families. Proc. Natl. Acad. Sci. U S A. 110:13880-5.

Dorji, D., Dendup, T., Malaty, H.M., et al., 2014. Epidemiology of Helicobacter pylori in Bhutan: the role of environment and Geographic location. Helicobacter. 19:69-73. 17

El Khadir, M., Boukhris, S.A., Benajah, D.A. et al., 2016. Detection of Helicobacter pylori antigen in saliva in patients with different gastric $H$. pylori status. $J$. Chin. Med. Assoc., 79:363-367

Elitsur, Y., Lawrence, Z., Hill, I. 2004. Stool antigen test for diagnosis of Helicobacter pylori infection in children with symptomatic disease: A Prospective Study. J. Pediatr. Gastroenterol. Nutr., 39(1):64-7.

El-Nasr, M.S., Elibiary, S.A., Bastawi, M.B., et al., 2003. Evaluation of a new enzyme immunoassay for the detection of Helicobacter pylori in stool specimens. J. Egypt Soc. Parasitol., 33(3):905-15.

Eshraghian, A. 2014. Epidemiology of Helicobacter pylori infection among the healthy population in Iran and countries of the Eastern Mediterranean Region: a systematic review of prevalence and risk factors. World J. Gastroenterol., 20: 17618-25.

Fahmy, S.I., Nofal 1.m., Shehata SF et al., 2015.Updating indicators for scaling the socioeconomic level of families for health research. J Egypt Public Health Assoc; 90 (1): 1-7.

Fialho, A.M., Braga, A.B., Braga, Neto, M.B., et al., 2010. Younger siblings play a major role in Helicobacter pylori transmission among children from a lowincome community in the Northeast of Brazil. Helicobacter. 15:491-6. 
Frenck, R.W., Fathy, H.M., Sherif, M., et al., 2006. Sensitivity and specificity of various tests for the diagnosis of Helicobacter pylori in Egyptian children. Pediatrics, 118:1195-1202.

Fujimoto, Y., Furusyo, N., Toyoda, K., et al., 2007. Intrafamilial transmission of Helicobacter pylori among the population of endemic areas in Japan. Helicobacter. 12:170-6.

Garza-González, E., Perez-Perez, G.I., Maldonado-Garza, H.J., et al., 2014. A review of Helicobacter pylori diagnosis, treatment, and methods to detect eradication. World. J. Gastroenterol., 20(6):1438-1449.

Ghosh, P., Bodhankar, S.L. 2012. Determination of risk factors and transmission pathways of Helicobacter pylori in asymptomatic subjects in western India using polymerase chain reaction. Asian Pac. J. Trop. Dis., 2(1):12-17.

Gulcan, E.M., Varol, A., Kutlu, T., et al., 2005. Helicobacter pylori stool antigen test. Indian J. Pediatr., 72(8):675-78.

Hanafi, M., Mohamed, A. 2013. Helicobacter pylori infection: seroprevalence and predictors among healthy individuals in Al Madinah, Saudi Arabia. J. Egypt. Public. Health Assoc., 88(1):40-45.

Hassanein, F.I., Shehata, A.I., Abdul-Ghani, R. 2017. G. lamblia and H. pylori infections among mentally challenged individuals in rehabilitation centers in Alexandria, Egypt. J. Infect. Dev. Ctries., 11(7):577-82.

Hu, Y., Zhang, M., Lu, B., et al., 2016. Helicobacter pylori and Antibiotic Resistance, A Continuing and Intractable Problem. Helicobacter, 21:349-363.

Hussain, S.A., Hamid. S. 2014. Helicobacter pylori in humans: Where are we now? Adv. Biomed. Res., 3: 63.
Ibrahim, A., Morais, S., Ferro, A., et al., 2017. Sex-differences in the prevalence of Helicobacter pylori infection in pediatric and adult populations: systematic review and meta-analysis of 244 studies. Dig. Liver Dis., 49:742749.

Ibtihal, N. 2010. Prevalence of Helicobacter pylori infection by different diagnostic methods. Iraqi. J. Pharm. Sci., 19(1).

Immunospec, Co., 2006. ELISA/EIA assays: H. pylori IgG. California: Immunospec; p.121. Available from: http://immunospec.com/productsELISA-EIA-assays.htm

Inoue, M. 2017. Changing epidemiology of Helicobacter pylori in Japan. Gastric. Cancer. 20:3-7.

Iqbal, S., Fatima, S., Raheem, A., et al., 2013. Agreement between serology and histology for detection of Helicobacter pylori infection. J. Coll. Phys. Surg. Pak. 23(10):784-786.

Ishaleku, D., Ihiabe, H. 2010. A.Seroprevalence of Helicobacter pylori infection among students of a Nigerian University. Asian Pac. J. Trop. Med., 10:584-585

Islam, M., Rahman, S., Shamsuzzaman, S.M., et al., 2010. A comparative study among different invasive methods for the diagnosis of Helicobacter pylori. Faridpur. Med. Coll. J., 5:21-24

Jafar, S., Jalil, A., Soheila, N., Sirous., S. 2013. Prevalence of Helicobacter pylori infection in children, a population-based cross-sectional study in west iran. Iran. J. Pediatr. 23(1):13-8.

Jemilohun, A.C., Otegbayo, J.A. 2016. Helicobacter pylori infection: past, present and future. Pan. Afr. Med. J., 23:216.

Jeong Y.Y., Nayoung K, Seung H., et al., 2007. Seroprevalence of Helicobacter pylori in South Korea. Helicobacter. 12: 333-340 
Kaore, N.M., Nagdeo, N.V., Thombare, V.R. 2012. Comparative Evaluation of the Diagnostic Tests for Helicobacter pylori and Dietary Influence for Its Acquisition in Dyspeptic Patients: A Rural Hospital Based Study in Central India. JCDR., 6:636-41.

Kaya, A.D., Gülen, D., Aydin, M., et al., 2014. Detection of $H$. pylori antigen in the stool samples of children, in Tekirdag. Turkey. Sci. Res., 6:865-9.

Khalifa, M.M., Sharaf, R.R., Aziz, K.K. 2010. Helicobacter pylori: a poor man's gut pathogen? Gut Pathogens., 2:2.

Khan, M.A., Ghazi, H.O. 2007. Helicobacter pylori infection in asymptomatic subjects in Makkah, Saudi Arabia. J. Pak. Med. Assoc., 57:114-7.

Kingsley I.O., Omasan H.O., Isaiah N.I., et al., 2017. Seroprevalence of Helicobacter pylori Infection and risk factors among asymptomatic subjects in Delta State. Nigeria Adv. Microbiol., 7:641-52

Kirkpatrick, L.A., Feeney, B.C. 2013. A simple guide to IBM SPSS statistics for version 20.0. Student ed. Belmont, Calif.: Wadsworth, Cengage Learning.

Kivi, M., Johansson, A.L., Reilly, M., et al., 2005. Helicobacter pylori status in family members as risk factors for infection in children. Epidemiol. Infect., 133:645-652.

Krueger, W.S., Hilborn, E.D., Converse, R.R., et al., 2015. Environmental risk factors associated with Helicobacter pylori seroprevalence in the United States: a cross-sectional analysis of NHANES data. Epidemiol. Infect., 143:2520-2531.

Kusters, J.G., van Vliet, A.H., Kuipers, E.J., 2006. Pathogenesis of Helicobacter pylori infection. Clin. Microbiol. Rev., 19(3):449-490.

Lario, S., Ramirez-Lazaro, M.J., Montserrat, A., et al., 2016. Diagnostic accuracy of three monoclonal stool tests in a large series of untreated Helicobacter pylori infected patients. Clin. Biochem., 49(9):682-687.

Laszewicz, W., Iwa'nczak, F., Iwa'nczak, B. 2014. Seroprevalence of Helicobacter pylori infection in Polish children and adults depending on socioeconomic status and living conditions. Adv. Med. Sci. 59(1):147-50.

Li, Y.H., Guo, H., Zhang, P.B., et al., 2004. Clinical value of Helicobacter pylori stool antigen test, ImmunoCard STAT $\mathrm{HpSA}$, for detecting $\mathrm{H}$ pylori infection. World J. Gastroenterol., 10(6):913-14.

Lim SH, Kwon JW, Kim N, et al., 2013. Prevalence and risk factors of Helicobacter pylori infection in Korea: nationwide multicenter study over 13 years. BMC. Gastroenterol., 13:104.

Malaty, H.M., ElKasaban, A.B., Graham, D.Y., et al., 2002. Age of Acquisition of Helicobacter pylori Infection: A Follow- up Study from Infancy to Adulthood. Lancet, 359:931-935.

Malfertheiner, P., Megraud, F., O’Morain, C.A., 2012. Management of Helicobacter pylori infection the Maastricht IV/ Florence Consensus Report. Gut, 61:e646-e664.

Mana, F., Vandebosch, S., Miendje Deyi, V., et al., 2013. Prevalence of and risk factors for $H$. pylori infection in healthy children and young adults in Belgium anno 2010/ 2011. Acta. Gastroenterol. Belg., 76:381-5.

Manfredi, M., Iuliano, S., Gismondi, P., et al., 2016. Helicobacter Pylori Infection: We Should Always Verify the Intrafamilial Transmission. Biol. Med. (Aligarh)., 9:366.

Manfredi, M., Maffini, V., de'Angelis, G.L. 2013. Epidemiology, transmission routes and recurrence of infection. In: Manfredi M, de'Angelis GL (eds.) Helicobacter pylori: detection methods, diseases and health implications. New 
York: Nova Science Publishers; pp: 101-12.

Marshall, B.J., Warren, J.R. 1984. Unidentified curved bacilli in the stomach of patients with gastritis and peptic ulceration. Lancet, 1:1311-1315.

Mathewos, B., Moges, B., Dagnew, M. 2013. Seroprevalence and trend of Helicobacter pylori infection in Gondar University Hospital among dyspeptic patients, Gondar, North West Ethiopia. BMC. Res. Notes., 6 (1):346.

McColl, K.E. 2010. Helicobacter pylori infection. N. Engl. J. Med., 362:15971604.

McLaughlin, N.J., McLaughlin, D.I., Lefcort, H. 2003. The influence of socioeconomic factors on Helicobacter pylori infection rates of students in rural Zambia. Cent. Afr. J. Med. 49:38-41.

Melo, E.T., Lopes, E.P., Almeida, J.R., et al., 2003. Seroprevalence of Helicobacter pylori antibodies in medical students and residents in Recife, Brazil. J. Clin. Gastroenterol., 36(2):134-8.

Mohamed O.N., El Zalabany M.M., Abaza, A.F. et al., 2016. Diagnosis of Helicobacter pylori infection in children and their mothers using some noninvasive techniques. Afr. J. Microbiol. Res., 10(31):1194-202.

Mohammad, M., AL Tayar, M., Toboli, A., et al., 2011. Characteristics of Helicobacter Pylori infection in Libyan healthy peoples in two teaching hospitals in Benghazi. Medical Journal of Islamic. World Acad. Sci., 19(1):2732.

Mohammad, M., Hussein, L., Coward, A., et al., 2008. Prevalence of Helicobacter pylori infection among Egyptian children: impact of social background and effect on growth. Public Health Nutr., 11(03):230-236.

Montazer-Saheb, S., Farajnia, S., Saeedi, N., et al., 2011. Seroprevalence of
Helicobacter pylori infection in patient suffering from gastric symptoms in North West of Iran. Afr. J. Microbiol. Res., 5(22):3616-9.

Muhammad, J.S., Zaidi, S.F., Sugiyama, T. 2012. Epidemiological ins and outs of Helicobacter pylori: a review. J. Pak. Med. Assoc. 62(9):955-9

Muhsen, K., Athamna, A., Bialik, A., et al., 2010. Presence of Helicobacter pylori in a sibling is associated with a long-term increased risk of $H$. pylori infection in Israeli Arab children. Helicobacter. 15:108-13.

Munish, R., Dolly, R., Shraddha S., et al., 2014. Prevalence of Helicobacter pylori in asymptomatic adult patients in a tertiary care hospital: A cross sectional study. Biomed. Res., 25 (4):117-22.

Nam, J.H., Choi, I.J., Cho, S.J., et al., 2011. Helicobacter pylori infection and histological changes in siblings of young gastric cancer patients. $J$. Gastroenterol. Hepatol., 26:1157-63.

Namakin, K., Nejad F.B. 2014. Prevalence of Helicobacter Pylori Infection in Asymptomatic Children in Birjand, Eastern Iran. Int. J. Pediatr., 2(Supplement 6): 4-2.

Naous, A., Al-Tannir, M., Naja, Z., et al., 2007. Seroprevalence and determinants of Helicobacter pylori infection among asymptomatic children in Lebanon. $J$. Med. Liban. 55: 138-44

Ni, Y.H., Lin, J.T., Huang, S.F., Yang, J.C., et al., 2000. Accurate diagnosis of Helicobacter pylori infection by stool antigen test and 6 other currently available tests in children. J. Pediatr., 136(6):823-7.

Nourai, M., Latifi-Navid, S., Rezvan, H., et al., 2009. Childhood Hygienic Practice and Family Education Status Determine the Prevalence of Helicobacter pylori Infection in Iran. Helicobacter, 14:4046. 
Olokoba, A.B., Gashau, W., Bwala, S., et al., 2013. Helicobacter pylori infection in Nigerians with dyspepsia. Ghana. Med. J., 47:79-81

Oluwasola, A.O., Ola, S.O., Saliu, L., et al., 2002. Helicobacter pylori infection in South Nigerians: a serological study of dyspeptic patients and healthy individuals. West Afr. J. Med., 21:13841.

Omosor, K.I., Omosor, O.H., Ibeh, I.N., et al., 2017. Seroprevalence of Helicobacter pylori Infection and Risk Factors among Asymptomatic Subjects in Delta State, Nigeria. Adv. Microbiol., 7:641-652.

Osaki, T., Okuda, M., Ueda, J., et al., 2013. Multilocus sequence typing of DNA from faecal specimens for the analysis of intra-familial transmission of Helicobacter pylori. J. Med. Microbiol. 62:761- 5 .

Osman, H.A., Hasan, H., Suppian, R., et al., 2014. Evaluation of the Atlas Helicobacter pylori stool antigen test for diagnosis of infection in adult patients. Asian. Pac. J. Cancer Prev., 15(13):5245-5247.

Ozaydin, N., Turkyilmaz, S.A., Cali, S. 2013. Prevalence and risk factors of Helicobacter pylori in Turkey: a nationally-representative, crosssectional, screening with the (1)(3)CUrea breath test. BMC. Public Health. 13:1215.

Pacheco, S.L., Ogata, S.K., Machado, R.S. et al., 2013. Diagnosis of Helicobacter pylori infection by means of reduceddose (13) C-urea breath test and early sampling of exhaled breath. J. Pediatr. Gastroenterol. Nutr., 57:607-11.

Pandya, H.B., Patel, J.S., Agravat, H.H., et al., 2014. Non-Invasive Diagnosis of Helicobacter pylori: Evaluation of two enzyme immunoassays, testing serum $\operatorname{IgG}$ and $\operatorname{Ig} \mathrm{A}$ response in the anand district of central Gujarat. India. J. Clin. Diagn. Res. 8(6):12-5.

Pastukh, N., Peretz, A., Brodsky, D., et al., 2018. Antimicrobial susceptibility of Helicobacter pylori strains isolated from children in Israel. J. Glob. Antimicrob. Resist., 12:175-178.

Perez-Perez, G.I., Rothenbacher, D., Brenner, H. 2004. Epidemiology of Helicobacter pylori infection. Helicobacter, 9:1-6.

Pourakbari, B., Ghazi, M., Mahmoudi, S., et al., 2013. Diagnosis of Helicobacter pylori infection by invasive and noninvasive tests. Braz. J. Microbiol., 44(3):795-8.

Queiroz, D.M., Saito, M., Rocha, G.A., et al., 2013. Helicobacter pylori infection in infants and toddlers in South America: concordance between [13C] urea breath test and monoclonal $H$. pylori stool antigen test. J. Clin. Microbiol. 51:3735-3740.

Rana, M. 2007. Risk factors associated with Helicobacter pylori infection in Gaza. Master Thesis, Science in Biological Science: Medical Technology. Egypt.

Ranjbar, R., Behzadi, P., Farshad, S.H., 2017. Advances in diagnosis and treatment of helicobacter pylori infection. Acta. Microbiol. Immunol. Hung., 64(3):273292.

Rastogi, M., Rastogi, D., Singh, S.H., et al., 2014. Prevalence of Helicobacter pylori in asymptomatic adult patients in a tertiary care hospital: A cross sectional study. Biomed. Res., 25(4):117-122.

Ravelomanana, L., Imbert, P., Kalach, N., et al., 2013. Helicobacter pylori infection in children in Madagascar: risk factors for acquisition. Trop. Gastroenterol., 34(4):244-251.

Ryu, K.H., Yi, S.Y., Na, Y.J., et al., 2010. Reinfection rate and endoscopic changes after successful eradication of Helicobacter pylori. World J. Gastroenterol., 16:251-5. 
Sabah, A.A., Gneidy, M.R., Saleh, N.M. 2015. Prevalence of Helicobacter pylori infection among adult patients with different gastrointestinal parasites in Tanta City district. J. Egypt Soc. Parasitol., 45:101-6.

Salih, B.A. 2009. Helicobacter pylori Infection in Developing Countries: The burden for How Long? Saudi. J. Gastroenterol. 15(30): 201-207.

Sethi, A., Chaudhuri, M., Kelly, L., et al., 2013. Prevalence of Helicobacter pylori in a First Nations population in northwestern Ontario. Can. Fam. Physician., 59:e182-7.

Seyda, T, Derya C, Fusun A., et al., 2007. The relationship of Helicobacter pylori positivity with age, sex and $\mathrm{ABO} L$ Rhesus blood groups in patients with gastrointestinal complaints in Turkey. Helicobacter. 12(3): 244-50.

Shah, S.A., Khan, A.A., Hussain, N., et al., 2014. Diagnostic accuracy of serology testing for Helicobacter Pylori in perforated peptic ulcer. J. Rawalpindi. Med. Col., 18(2):250-3

Sharbatdaran. M., Kashifard, M., Shefaee, S.H., et al., 2013. Comparison of stool antigen test with gastric biopsy for the detection of Helicobacter Pylori infection. Pak. J. Med. Sci., 29(1):6871.

Sheehan, K.M., Byrne, M.F., Murray, F.E. 2004. The seroprevalence of Helicobacter pylori in an Irish university student population. J. Infect., 48(3):283-4.

Shimoyama, T. 2013. Stool antigen tests for the management of Helicobacter pylori infection. World J. Gastroenterol., 19(45):8188-8191

Silva Rossi, A.V., Navarro, R.T., Mattar, R., et al., 2009. Oral cavity is not a reservoir for Helicobacter pylori in infected patients wi functional dyspepsia. Oral. Microbiol. Immunol., 24(3):255-9.

Sodhi, J.S., Javid, G., Zargar, S.A., et al., 2013. Prevalence of Helicobacter pylori infection and the effect of its eradication on symptoms of functional dyspepsia in Kashmir India. J. Gastroenterol. Hepatol., 28:808-13.

Songhua, Z., Leonard, M., Steven, F., et al., 2011. H. pylori vaccines. Human Vaccines, 7(11):1153-7.

Tadege, T., Mengistu, Y., Desta K., et al., 2005. Seroprevalence of Helicobacter pylori infection and its relationship with ABO Blood groups. Ethio. J. Health Dev., 19(1):55-60

Tameshkel, F.S., Niya, M.H., Kheyri, Z., et al., 2018. The evaluation of diagnostic and predictive values of Helicobacter pylori stool antigen test in Iranian patients with dyspepsia. Iran. J. Pathol., 13(1):38-44.

Taneike, Y., Tamura, Y., Shimizu, T. et al., 2001. Helicobacter pylori intrafamilial infections: change in source of infection of a child from father to mother after eradication therapy. Clin. Diagn. Lab. Immunol., 8:731-739.

Urita, Y., Watanabe, T., Kawagoe, N., et al., 2013. Role of infected grandmothers in transmission of Helicobacter pylori to children in a Japanese rural town. $J$. Paediatr. Child Health 2013; 49: 394 8.

Vale, F.F., Vítor, J.M. 2010. Transmission pathway of Helicobacter pylori: does food play a role in rural and urban areas? Int. J. Food Microbiol., 138:112.

Valliani, A., Khan, F., Chagani, B., et al., 2013. Factors Associated with Helicobacter pylori infection, results from a developing country-Pakistan. Asian Pac. J. Canc. Prev., 14(1):53-6.

Van Blankenstein, M., van Vuuren, A.J., Looman, C.W., et al., 2013. The 
prevalence of Helicobacter pylori infection in the Netherlands. Scand. $J$. Gastroenterol., 48:794-800.

Vilaichone, R.K., Mahachai, V., Shiota, S., et al., 2013. Extremely high prevalence of Helicobacter pylori infection in Bhutan. World. J. Gastroenterol., 19:2806-10.

Wangda, S., Richter, J.M., Kuenzang, P., et al., 2017. Epidemiology of Helicobacter pylori infection in asymptomatic schoolchildren in Bhutan. Helicobacter, 22:e12439.

Whalen, M.B., Massidda, O. 2015. Helicobacter pylori: enemy, commensal or, sometimes, friend? J. Infect. Dev. Ctries., 9(6):674-678.

Yan, T.L., Hu, Q.D., Zhang, Q., et al., 2013. National rates of Helicobacter pylori recurrence are significantly and inversely correlated with human development index. Aliment. Pharmacol. Ther., 37:963-968.

Yang, H.R., Seo, J.K. 2008. Helicobacter pylori Stool Antigen (HpSA) Tests in Children Before and After Eradication Therapy: Comparison of Rapid Immunochromatographic Assay and HpSA ELISA. Dig. Dis. Sci., 53(8):2053-8.
Yordanov, D., Boyanova, L., Markovska, R., et al., 2017. Influence of dietary factors on Helicobacter pylori and CagA Seroprevalence in Bulgaria. Gastroenterol. Res. Pract., 2017: 9212143.

Yu, X., Yang, X., Yang, T., et al., 2017. Dong Q, Wang L, Feng L. Decreasing prevalence of Helicobacter pylori according to birth cohorts in urban China. Turk. J. Gastroenterol., 28:94-7.

Zamani, M., Ebrahimtabar, F., Zamani, V., et al., 2018. Review with meta-analysis: the worldwide prevalence of Helicobacter pylori infection. Aliment Pharmacol. Ther., 47:868-876.

Zhong, Y., Anderl, F., Kruse, T., et al., 2016. Helicobacter pylori HP0231 influences bacterial virulence and is essential for gastric colonization. PLoS One, 11:e0154643.

Zhu, Y., Zhou, X., Wu, J., et al., 2014. Risk factors and prevalence of Helicobacter pylori infection in persistent high incidence area of gastric carcinoma in Yangzhong city. Gastroenterol. Res. Pract., 2014:481365.

\section{How to cite this article:}

Hadir EL-Kady. 2018. Screening for Helicobacter pylori Infection among Asymptomatic University Students in Alexandria, Egypt, Using Non Invasive Laboratory Techniques. Int.J.Curr.Microbiol.App.Sci. 7(06): 2136-2155. doi: https://doi.org/10.20546/ijcmas.2018.706.254 